\title{
The Relationship of Higher Education Access with Final Marks in a Core Chemical Engineering Topic
}

\author{
M. Teresa Sena-Esteves ${ }^{\dagger}$ \\ CIETI Research Centre, Polytechnic \\ of Porto, Porto, Portugal \\ mte@isep.ipp.pt \\ Isabel Brás Pereira \\ CIETI Research Centre, Polytechnic \\ of Porto, Porto, Portugal \\ imp@isep.ipp.pt
}

\author{
Cristina Morais \\ CIETI Research Centre, Polytechnic \\ of Porto, Porto, Portugal \\ lcm@isep.ipp.pt \\ Anabela Guedes \\ CIETI Research Centre, Polytechnic \\ of Porto, Porto, Portugal \\ afg@isep.ipp.pt \\ Celina Pinto Leão \\ ALGORITMI, DPS , School of \\ Engineering, University of Minho, \\ Guimarães, Portugal \\ cpl@dps.uminho.pt
}

\author{
Margarida Ribeiro \\ CIETI Research Centre, Polytechnic \\ of Porto, Porto, Portugal \\ mgr@isep.ipp.pt \\ Filomena Soares \\ ALGORITMI Centre, DEI, School of \\ Engineering, University of Minho, \\ Guimarães, Portugal \\ fsoares@dei.uminho.pt
}

\begin{abstract}
This present work cracks to understand the relationship between final marks in a topic with competences that are core of Chemical Engineering and students' access grades to a Portuguese Higher Education Institution (HEI). The study is based on data gathered through a questionnaire concerning students' perceptions about assessment and teaching-learning methodologies in four academic years (2016-2017 to 2019-2020). The student's access grades were included in the questionnaire since 2018-19 academic year allowing to establish a relationship with the final marks obtained in a core Chemical Engineering Topic, Fluid Mechanics. From the analysis made, it can be said that students who obtained higher access grades to HEI may have also a higher Chemical Engineering curricular unit final mark, although the low linear relationship obtained $(\mathrm{r}$ $=0.45$ ) for the year 2019-20.
\end{abstract}

\section{CCS CONCEPTS}

- Social and professional topics $\rightarrow$ Professional topics; Computing education; Student assessment.

\section{KEYWORDS}

Students Perceptions, Engineering Education, Assessment, Fluid Mechanics Competences

Permission to make digital or hard copies of all or part of this work for personal or classroom use is granted without fee provided that copies are not made or distributed for profit or commercial advantage and that copies bear this notice and the full citation on the first page. Copyrights for components of this work owned by others than ACM must be honored. Abstracting with credit is permitted. To copy otherwise, or republish, to post on servers or to redistribute to lists, requires prior specific permission and/or a fee. Request permissions from permissions@acm.org.

TEEM'20, October 21-23, 2020, Salamanca, Spain

(C) 2020 Association for Computing Machinery.

ACM ISBN 978-1-4503-8850-4/20/10 . \$ \$15.00

https://doi.org/10.1145/3434780.3436667
ACM Reference Format:

M. Teresa Sena-Esteves ${ }^{\dagger}$, Cristina Morais, Margarida Ribeiro, Isabel Brás Pereira, Anabela Guedes, Filomena Soares, and Celina Pinto Leão. 2020. The Relationship of Higher Education Access with Final Marks in a Core Chemical Engineering Topic. In Eighth International Conference on Technological Ecosystems for Enhancing Multiculturality (TEEM'20), October 2123, 2020, Salamanca, Spain. ACM, New York, NY, USA, 7 pages. https: //doi.org/10.1145/3434780.3436667

\section{INTRODUCTION}

When students finish their twelve years school program in Portugal they may apply for university/polytechnic studies, although in certain areas of studies (like arts, sports, etc.) students first have to fulfill specific prerequisites. In Portugal one of the key factor to enter university/polytechnic studies is student's high school performance, quantified in an overall grade. This grade is calculated taking into account students' performance in the last three years weighted with national exams, particularly the exams conducted in the core areas of studies. These core exams, for example Mathematics and Physics when applying to an Engineering course, value $30 \%$ or even $50 \%$, in some universities/polytechnic schools, of the access grade. Students are then ranked in descending order according to their access grade, fulfilling the number of available places for the specific course. Entering university/ polytechnic schools depends almost exclusively on students' high school grade (in polytechnic schools there is also the so called regional preference which allows students with lower grades and living in the region of the polytechnic schools to access up to $50 \%$ of the places available). Students' high school access grade is a necessary condition to enter university but is it sufficient to the future students' academic success and professional life? Are there any other indicators that may influence the academic performance?

Some studies can be found in the literature focused on the factors that may influence students' success in the university [1-4]. As 
the selection process to enter universities is often the high school Grade Point Average (GPA), this is the main focus in the researches. Nevertheless, other indicators as students' socio-economic and educational background, social status, type of schools are also evaluated.

Philippe and Chan [4], in their study in Manitoba high school and the University of Winnipeg, found that student's high school grade is a strong predictor of their university success, but other factors are greater high school parent's expenditures, more favorable neighborhood effects, and greater student resources.

Regarding socio-economic background, parental education and family income were factors studied when analyzing the determinants of student performance at university [5-8]. Guimarães and Sampaio [7] and Spiess and Wrohlich [8] concluded that parents' education has a positive impact on accessing university. Nevertheless, Spiess and Wrohlich [8] found parents' income and family status insignificant.

Other factors that may influence students' academic success are referred in the literature as the importance of self-efficacy and achievement motivation [9, 10], and emotional intelligence [11].

In this reflection we are not considering the pro-active measures the universities may follow, as the implementation of coaching programs, in order to mitigate students' adaptation to college environment $[12,13]$.

The positive effect of high school grades on the academic success is not valid for all areas of studies $[6,14,15]$. Considering in particular the Engineering area in Monash University (Australia), Dobson and Skuja [15] found a strong correlation between the university entrance grades and students' academic performance.

Following this trend, the goal of this study is to infer if there is a relationship between GPA in an engineering course and the academic success in a core topic in Chemical Engineering studies, Fluid Mechanics.

The present paper is organized in four sections. Section 1 shows the global interest in the main topic of this study. Section 2 presents the curricular unit under study and the questionnaire used to gather data for analyses. In section 3 results are presented and discussed. Finally in section 4 conclusions are drawn.

\section{MATERIAL AND METHODS}

In this section are presented the description of the curricular unit, Fluid Transport Systems (STFLU), where the data was collected and the description of the instrument used to collect the data. The time period of the study is also identified.

\subsection{Curricular Unit Characterization}

ISEP (Instituto Superior de Engenharia do Porto, in Portuguese), the Higher Education Institution (HEI) where STFLU is thought, offers two cycles of higher education in Chemical Engineering: the 3 years Bachelor's (first cycle) and the Master's (2 years). The first cycle provides fundamental skills for the exercise of chemical engineering in various fields and positions, while the Master's degree allows for more in-depth knowledge in the main areas of Chemical Engineering as well as specific skills in Energy and Biorefinery or in Quality or in Technologies of Environmental Protection.
Fluid Transport Systems (STFLU) is a course of the second year of the first cycle in Chemical Engineering of ISEP. It has one hour of lectures and three hours of practical classes per week. Each year, an average number of 55 to 60 students attend this course either in daytime or evening classes. In lectures expository and interrogative methods (questions/problems and mini tests) are predominant but demonstrative and active techniques are used as well (practical work). Problems and real case studies are also proposed for students to solve.

Fluid Transport Systems has the general objective of giving students fundamental knowledge in Fluid Mechanics.

Students learn how to make mass and energy balances useful for designing fluid transport systems. The selection of appropriate pumps, both in type and power, flow meters, compressors and fans is also an important topic of the course syllabus.

In Fluid Transport Systems, all students must do a Practical Work (PW), preferably in group, accounting for $15 \%$ weight in the final grade. In addition to PW, students may choose between continuous assessment with four individual mini-tests (IMT1-8\%, IMT2-8\%, IMT3-17.5\%, IM4-50\%) and one team/group mini-test (GMT1-1.5\%) along the semester or a Final Exam $\left(1^{\text {st }} \mathrm{E}\right.$ or/and $\left.2{ }^{\text {nd }} \mathrm{E}-85 \%\right)$. Since $2017 / 2018$ a minimum score of 8.0 out of 20 in mini-test IMT4 is required while the other three mini-test (IMT1, IMT2 and IMT3) remain without this restriction.

\subsection{Instrument Description}

Data used to fulfil the main objective of this work, were not only the final marks of each student but also the students' perceptions based on a questionnaire developed for that purpose [17].

The referred questionnaire intended to collect students' perceptions regarding teaching/learning techniques and the assessment methodologies [16-18]. It was based in a previous questionnaire already used to study the impact of introducing a PW in the learning process of the Fluid Transport Systems course in the Chemical Engineering degree [18].

The present questionnaire includes, in a simplified way, seven main parts:

- Student's characterization (gender, age, academic year, class timetable, class attendance, HEI access grade - added in 2018/2019);

- Student's perception regarding his/her typical learning style and the learning style they used during the development of the PW. The learning styles used were based on Kolb theory [20];

- Technical Skills (TS) acquired through the PW; 12 items from which 7 are evaluated according to a 5-point Likert scale (1Very Poor, 2-Poor, 3-Average, 4-Good, 5-Very Good) and the remaining with a "No/Yes" answer;

- Concept Understanding (CUnd) with PW development, evidenced by a group of sentences given as multiple choice based on 5 sentences;

- Soft Skills (SS) acquired through the PW development; 5 items evaluated according to a 5-point Likert scale of agreement (1-strongly disagree, 2-disagree, 3-neither agree nor disagree, 4-agree, 5-strongly agree); 
- Course Organization and Functioning (COF): 15 items, of which 14 are evaluated according to a 5-point Likert scale of agreement (1-strongly disagree, 2-disagree, 3-neither agree nor disagree, 4-agree, 5-strongly agree) and one with multiple choice;

- Activity Effectiveness (AE), which compares teaching methodologies: 5 items evaluated according to a 5-point Likert scale of agreement (1-lowest effectiveness to 5-highest effectiveness).

More detailed information regarding the questionnaire can be found elsewhere [16-18].

The printed questionnaire was handed out to students after an individual assessment test (IMT4), in the 1st semester of 2016/17 to 2019/20 academic years. Before starting to fill in the questionnaire, students were informed about the objectives of the study. It was answered on a voluntary basis and its completion did not take more than about 10 minutes.

\subsection{Sample Characterization}

Data updated from 2016/17 to 2019/20 was considered. The main characteristics are summarized in Table 1 , based on a total sample of 222 students. This number represents around $92 \%$ of the total number of enrolled students.

In the 222 students' sample, the majority (71.3\%) was of female gender. All students were aged between 19 and 48 (average 20.0 years with $\mathrm{SD}=3.08$ ), and $61.9 \%$ of them were 19 years old.

A large majority of the students (96.0\%) attended the course in daytime classes and the remaining enrolled in after working classes.

A very small number of students (representing 1.3\%) was attending the course for the third time and for the majority of them $(91.0 \%)$ this was their first enrollment in Fluid Transport Systems.

The data collected was analyzed by non-parametric tests (Kruskal-Wallis, $H$, for the comparison of more than two independent samples means, and the Spearman's correlation coefficient, $r_{S}$, to study and measure the strength of the relationship between two ranked variables/items) since they do not follow normality (normality verified by Shapiro-Wilk test).

The statistical software SPSS 25.0 was used for the analysis, and consider a statistical significant differences for $p<0.05$ [21].

\section{RESULTS AND DISCUSSION}

Based on results obtained in a previous study [21], although female students usually, in average, finish STFLU with higher final marks than their male counterparts, these differences are not statistically significant. So from now on the analysis will be done on an aggregated basis.

\subsection{Students' Final Marks}

In this section, the students' final mark in the curricular unit STFLU will be analyzed in the last four academic years: from 2016/17 to 2019/20. Table 2, shows the aggregated statistical data.

The difference between the different final students' marks in the four academic years is statistically significant $(H(3)=8.29, p=$ 0.04 , with a mean rank final mark score of 131.70 for $2019 / 20,106.71$ and 106.62 for 2016/17 and 2017/18, respectively, and 99.91 for 2018/19, according to Kruskal-Wallis, $H$ non-parametric statistical
Table 1: Main Students' Characteristics

\begin{tabular}{llllll}
\hline Academic Year & $16 / 17$ & $17 / 18$ & $18 / 19$ & $19 / 20$ & Total \\
\hline $\mathrm{n}$ & 50 & 57 & 57 & 58 & 222 \\
Gender & & & & & \\
Male (\%) & 32.0 & 27.6 & 31.6 & 24.1 & 28.7 \\
Female (\%) & 68.0 & 72.4 & 68.4 & 75.9 & 71.3 \\
Age (\%) & & & & & \\
19 & 78.0 & 56.9 & 42.1 & 72.4 & 61.9 \\
$20<>21$ & 14.0 & 32.7 & 50.9 & 19.0 & 29.2 \\
$\geq 22$ & 8.0 & 10.4 & 7.0 & 8.6 & 8.9 \\
Mean Age & 19.5 & 19.9 & 20.5 & 20.1 & 20.0 \\
St. Deviation & 1.17 & 1.62 & 4.47 & 3.93 & 3.08 \\
Regime of Class & & & & & \\
Daytime (\%) & 98.0 & 93.0 & 96.5 & 98.3 & 96.0 \\
After work (\%) & 2.0 & 7.0 & 3.5 & 1.7 & 4.0 \\
$1^{\text {st Time }}$ & 84.0 & 89.5 & 100 & 91.4 & 91.0 \\
Attending & & & & & \\
Students (\%) & & & & & \\
HEI access grade & & & & & \\
n. & - & - & 49 & 49 & 98 \\
Mean & - & - & 15.4 & 15.8 & 15.6 \\
St. deviation & - & - & 1.09 & $0.99-$ & 1.05 \\
\hline
\end{tabular}

Table 2: Students' Final Mark Statistics by Academic Year

\begin{tabular}{ccccccc}
\hline $\begin{array}{c}\text { Academic } \\
\text { year }\end{array}$ & min & max & median & mean & s.d. & $\begin{array}{c}\text { Statistic } \\
H\end{array}$ \\
\hline $2016 / 17$ & 5.0 & 18.0 & 12.0 & 12.8 & 2.87 & $8.29^{*}$ \\
$2017 / 18$ & 7.0 & 17.0 & 12.0 & 12.8 & 2.37 & \\
$2018 / 19$ & 4.0 & 18.0 & 12.0 & 12.4 & 2.87 & \\
$2019 / 20$ & 3.0 & 19.0 & 14.0 & 13.6 & 2.81 & \\
Total & 3.0 & 19.0 & 13.0 & 12.9 & 2.75 & \\
\hline
\end{tabular}

* significant at 0.05 level / s.d. standard deviation

test). From the four academic years, it was found a significant difference in the final marks of 2019/20 where, in average, was obtained the highest value. It is important to emphasize that in all these academic years assessment methodology was all the same. For the remaining three academic years, the differences between them are not statistically significant $(H(2)=0.40, p=0.82)$.

Trying to understand what reasons may be behind this behaviour, a detail analysis on the students' attendance in the theoretical classes was performed. Figure 1 shows the attendance percentage in theoretical classes along the semester weeks of 2018/2019 and 2019/2020 based on enrolled students. According to this figure students attend more than $90 \%$ when assessment moments occur (IMT1, TGT1, IMT2, IMT3 and IMT4). As theoretical classes are not mandatory students tend to skip theses type of teaching format when they presume it is not profitable for them. This is evident from the low attendance in weeks with no assessment. Comparing year $2018 / 2019$ with $2019 / 2020$, the attendance to classes with no assessment is higher in the last year. To a certain extent, this behaviour may explain the statistical differences observed in the final marks 


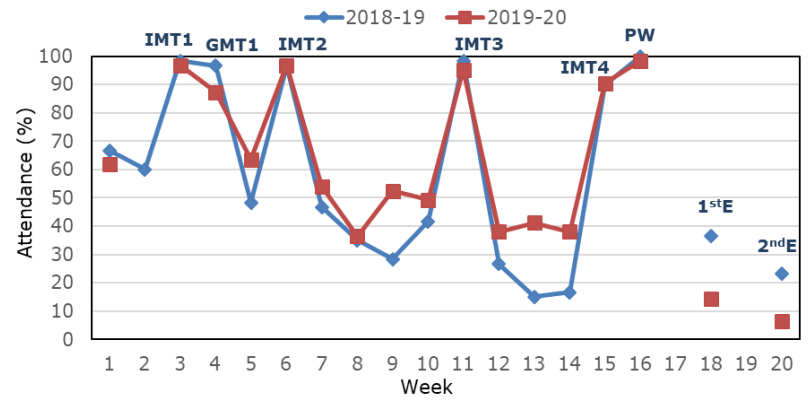

Figure 1: Attendance to theoretical class throughout the weeks of academic years 2018/19 and 2019/20. IMT: Individual Mini-Test, TGT: Team/Group Test, PW: Practical Work, E: Final Exam (normal, 1st, and supplementary, 2nd)

of 2019/20 in comparison with the previous academic years (Table 2). Better final results in the assessment along the semester occur in 2019/2020 with approximately $83 \%$ rate of approval (based on enrolled students) whereas $61 \%$ was obtained in 2018/2019 which explains less presences in 2019/2020 final exams $\left(1^{\text {st }} \mathrm{E}\right.$ and $\left.2^{\text {nd }} \mathrm{E}\right)$. The relatively high attendance to final exam $1^{\text {st }} \mathrm{E}$ in $2018 / 2019$ is due to students that did not reach the minimum grade required in assessment moment IMT4 (around 18\% in 2018/2019 and 3\% in 2019/2020, based on enrolled students).

The following step was to develop a cluster analysis based on the understanding of the STFLU students' final mark data obtained in the four academic years. This cluster analysis will allow to identify homogeneous groups of students established on the similarity within it, i.e., clustering students according to their STFLU final marks. The clusters of similar marks can help identifying similar behaviors and perceptions regarding Activity Effectiveness (AE) and Course Organization and Functioning (COF) (analyses detailed in the next subsection).

For the cluster analysis, STFLU students' final mark obtained in 2016/17 to 2019/20 academic years were considered and presented graphically, enabling an easier identification of distinctive behaviors. Figure 2 illustrates the distribution of the students' STFLU final marks versus academic year (more specifically, the year of the end of the semester). For each academic year, the sizes of the bubbles are according to the number of students with a specific mark: smaller bubbles indicate fewer students with s specific mark, and larger bubbles represent higher number of students with a specific mark. For example, for the academic year 2017/18, twelve students obtained the mark 12 and 11 (the two circles with greater diameter), and ten students obtained 16.

Easily three groups emerge: lower, medium and high marks that are confirmed through a cluster analysis. So, for the cluster analysis, the method of k-means was used considering 3, the number of clusters to extract, as input. From the analysis three groups were highlighted in Figure 2 not approved students with marks lower than 10 and identified as "Lower Students' Mark" (LSM), students approved with final mark lower or equal to 13 and identified as "Medium Students' Mark" (MSM), and students approved with final mark higher or equal to 14 and identified as "Higher Students'

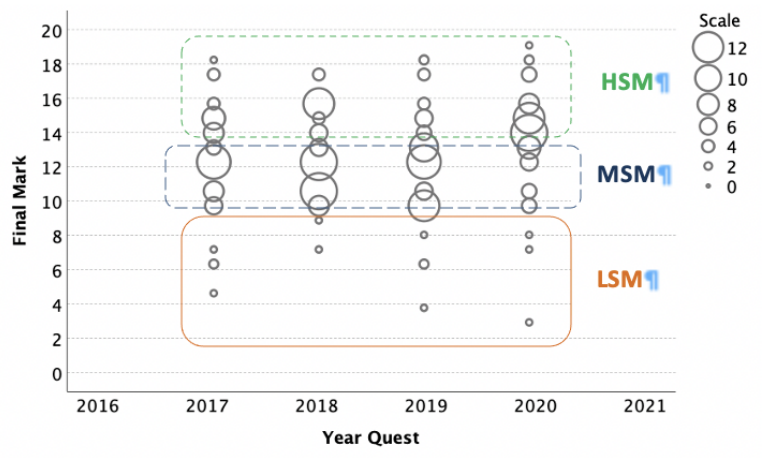

Figure 2: STFLU final marks versus Academic Year (semester's end) and clusters

Table 3: Students' Final Mark Statistics in each cluster by Academic Year

\begin{tabular}{ccccccc}
\hline $\begin{array}{c}\text { Academic } \\
\text { year }\end{array}$ & \multicolumn{2}{c}{ LSM n3 $=13$} & \multicolumn{2}{c}{ MSM n2=116 } & \multicolumn{2}{c}{ HSM n1=93 } \\
\cline { 2 - 7 } & mean & s.d. & mean & s.d. & mean & s.d. \\
$2016 / 17$ & 6.0 & 0.82 & 11.5 & 0.99 & 15.3 & 1.22 \\
$2017 / 18$ & 8.0 & 1.41 & 11.5 & 0.95 & 15.5 & 1.03 \\
$2018 / 19$ & 6.0 & 1.63 & 11.5 & 1.17 & 15.6 & 1.37 \\
$2019 / 20$ & 6.0 & 2.65 & 11.8 & 1.16 & 15.3 & 1.37 \\
Total & 6.3 & 1.65 & 11.6 & 1.1 & 15.4 & 1.25 \\
\hline
\end{tabular}

s.d. standard deviation

Mark" (HSM). Table 3 presents the statistics for the students' final marks in each of the homogeneous clusters defined. Notice that the cluster with high number of students $(\mathrm{n} 2=116)$ corresponds to the "Medium Students' Mark" (MSM), that is, students with final mark between 10 and 13 (out of 20), is somehow expected and normal for STFLU.

\subsection{Students' Activity Effectiveness by Cluster}

The clusters division will be used to analyze the data considering the students' perceptions regarding part 7 of the questionnaire Activity Effectiveness (AE), which compares teaching methodologies with 5 items evaluated according to a 5-point Likert scale of agreement (1-lowest effectiveness to 5-highest effectiveness), according to the following five items:

AE1-theoretical class where the teacher lectures the contents and a theoretical-practical class where applied exercises are solved,

AE2-previous study of theoretical concepts proposed by the teacher and discussion in theoretical class of the application of these concepts,

AE3-students individually solve a global question in the theoretical class using the knowledge they have,

AE4-theoretical class where the teacher presents the contents using practical examples and a theoretical-practical class where applied exercises are solved, 
Table 4: Students' Final Mark Statistics by Activity Effectiveness (AE) and Cluster

\begin{tabular}{|c|c|c|c|c|c|c|c|}
\hline item & cluster & $\min$ & $\max$ & median & mean & s.d. & Statistic $H$ \\
\hline \multirow[t]{3}{*}{ AE1 } & LSM & 3 & 5 & 4 & 4.14 & 0.555 & 2.91 \\
\hline & MSM & 2 & 5 & 4 & 4.04 & 0.724 & \\
\hline & HSM & 2 & 5 & 4 & 4.21 & 0.695 & \\
\hline \multirow[t]{3}{*}{$\mathrm{AE} 2$} & LSM & 2 & 5 & 4 & 3.62 & 0.870 & 1.10 \\
\hline & MSM & 1 & 5 & 4 & 3.59 & 1.023 & \\
\hline & HSM & 1 & 5 & 4 & 3.43 & 1.050 & \\
\hline \multirow[t]{3}{*}{ AE3 } & LSM & 2 & 5 & 4 & 4.00 & 0.913 & 3.03 \\
\hline & MSM & 1 & 5 & 4 & 3.64 & 1.030 & \\
\hline & HSM & 1 & 5 & 4 & 3.83 & 0.915 & \\
\hline \multirow[t]{3}{*}{$\mathrm{AE} 4$} & LSM & 1 & 5 & 4 & 4.00 & 1.225 & 1.32 \\
\hline & MSM & 2 & 5 & 4 & 4.30 & 0.680 & \\
\hline & HSM & 1 & 5 & 4 & 4.38 & 0.696 & \\
\hline \multirow[t]{3}{*}{ AE5 } & LSM & 3 & 5 & 4 & 4.15 & 0.689 & 4.35 \\
\hline & MSM & 2 & 5 & 4 & 4.06 & 0.794 & \\
\hline & HSM & 1 & 5 & 4 & 3.78 & 0.980 & \\
\hline
\end{tabular}

s.d. standard deviation

Table 5: Students' Final Mark Statistics by three items of Course Organization and Functioning (COF) and Cluster

\begin{tabular}{|c|c|c|c|c|c|c|c|}
\hline item & cluster & $\min$ & $\max$ & median & mean & s.d. & Statistic $H$ \\
\hline \multirow[t]{3}{*}{ COF12 } & LSM & 3 & 5 & 4 & 4.08 & 0.760 & $12.61^{*}$ \\
\hline & MSM & 1 & 5 & 4 & 3.79 & 1.145 & \\
\hline & HSM & 2 & 5 & 4 & 4.34 & 0.752 & \\
\hline \multirow[t]{3}{*}{ COF13 } & LSM & 2 & 5 & 4 & 3.62 & 0.961 & $11.47^{*}$ \\
\hline & MSM & 1 & 5 & 4 & 3.65 & 1.217 & \\
\hline & HSM & 1 & 5 & 4 & 4.14 & 1.001 & \\
\hline \multirow[t]{3}{*}{ COF14 } & LSM & 1 & 4 & 1 & 1.54 & 0.967 & $10.96^{*}$ \\
\hline & MSM & 1 & 5 & 2 & 2.38 & 1.435 & \\
\hline & HSM & 1 & 5 & 1 & 1.83 & 1.154 & \\
\hline
\end{tabular}

* significant at the 0.001 level / s.d. standard deviation

AE5-students solve a problem in groups in the theoretical class using the knowledge they have.

This type of items will allow to decide in the future if it is possible, in the student's point of view, further changes in the way theoretical classes are taught towards TBL (Team Based Learning) since a part of the assessment is based in team and collaborative work.

Table 4 presents the corresponding statistics in terms of minimum, maximum, median, mean and standard deviation values obtained according to the three students' final marks clusters defined.

For the five Activity Effectiveness items, on average, students demonstrated to be in agreement (mean values around 4 and median values equal 4). It is worth to emphasize that $\mathrm{AE} 1$ and $\mathrm{AE} 4$ have the highest evaluations. AE1 is related to student's preference to solve exercises only after the teacher lectures the correspondent theoretical contents and AE4 is the same but with the difference that the teachers presents the contents using practical examples in theoretical classes.
Also, three of 14 items of part 6 of the questionnaire Course Organization and Functioning (COF), evaluated according to a 5point Likert scale of agreement (1-strongly disagree to 5-strongly agree) were considered and analyzed by cluster:

COF12: The evaluation through questions/problems and small tests during theoretical lessons was beneficial to my learning.

COF13: For the intermediate assessment, I prefer several questions/problems and small tests during theoretical classes.

COF14: For the intermediate assessment, I prefer to carry out a single moment of evaluation/test.

Table 5 presents the corresponding statistics in terms of minimum, maximum, median, mean and standard deviation values obtained according to the three students' final marks clusters defined.

As expected, on average, the lowest result obtained was for COF14 (For the intermediate assessment, I prefer to carry out a single moment of evaluation and test) with average values lower than 3 , showing a disagreement in opinion. A negative evaluation manifests a positive perception that it would be preferable to have more than one moment of assessment [18]. 


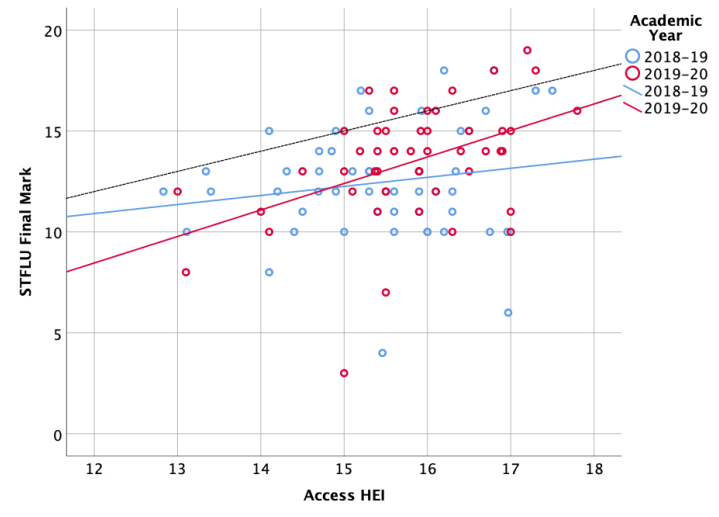

Figure 3: STFLU final marks versus Access grades to HEI for 2018-19 and 2019-20 academic years

However, and in contrast with the previous set of items (AE's), there is a statistically significant difference between the three clusters for each of the three COF items (for all the items under analysis: $p<0.001)$. In COF12 and COF13 students with higher final marks (HSM cluster) show a tendency for a different behaviour in comparison with the other two, being in agreement with that the evaluation through questions/problems and small tests was beneficial to their learning and preferring several questions/problems and small tests during theoretical classes.

\subsection{Relationship between Access Grades to HEI and STFLU Final Marks}

The next step of the study was to obtain and to identify the relationship which exists between students' access mark to HEI and students' STFLU final mark.

For the analysis and due to the confidentiality of data and the protection of personal data, only the two past academic years (201819 and 2019-20) were considered. The data available was submitted by the students themselves in the questionnaire since 2018-19. The questionnaires without this data (around $15 \%$ of the total received) is only due to the fact that the students said they did not remember anymore this information but allowed us to gather it, which was decided not to do since the authorization was not written.

Figure 3 shows the two lines estimated based on the data. So, based on a simple linear regression it will possible to establish how the access HEI influences the STFLU final mark, in others words, to know if a linear equation can be used for prediction of STFLU final mark based on the student's access grade to HEI.

Based on the data obtained, for both academic years, the trend is that STFLU's final marks change in the same direction as the access grades to HEI that is, both show a positive correlation. Nevertheless, for 2018-19 academic year, access grades to HEI and STFLU final marks data present a low positive correlation $(r=0.17$, blue line $)$ in contrast with the academic year 2019-20 data that show a moderate positive and significant correlation $(\mathrm{r}=0.45$, in $2019-20$, red line; $\mathrm{p}<0.01$ ). It must be pointed out that is in this last academic year students received the highest mark in average. So, it could be said that students who obtained higher access grades to HEI may receive also a higher STFLU final mark. It can be noted that the linear regression line for 2019-20 has a growth profile tendency nearly parallel to the line defined when both variable are equal (dashed black line).

\section{CONCLUSIONS AND FUTURE WORK}

The goal of this study is to infer if there is a relationship between students' access grade to HEI in an engineering course and the academic success in a core topic in Chemical Engineering studies, Fluid Mechanics.

There is a positive trend between access grades to HEI and STFLU final marks, for the two academic years analysed, with a significant correlation $(\mathrm{p}<0.01)$ for $2019-20$. So, it could be said that students who obtained higher access grades to HEI may receive also a higher STFLU final mark.

A further cluster analysis was made which allowed to identify homogeneous groups of students clustering students according to their STFLU final marks. The clusters of similar marks helped to identify similar behaviors and perceptions regarding Activity Effectiveness (AE) and Course Organization and Functioning (COF). It was concluded that students from HSM (Higher Students' Marks) cluster have, on average, a tendency to evaluate with the lowest mean values $\mathrm{AE}$ items with an exception for $\mathrm{AE} 4$ and $\mathrm{AE} 1$ which reinforces the hypothesis of a relation between the presence in theoretical classes and higher final marks and that teacher's presence is important for students. In terms of $\mathrm{COF}^{\prime} \mathrm{s}$ items all clusters results showed that on average students have a negative perception concerning one single moment of evaluation. HSM cluster students show a tendency for a different behaviour in comparison with the other two clusters (LSM and MSM), being in agreement the idea that evaluation through questions/problems and small tests was beneficial to their learning and preferring several questions/problems and small tests during theoretical classes.

In what concerns the attendance to theoretical classes as they are not mandatory, students tend to skip this type of teaching format. More than $90 \%$ of the enrolled students attend theoretical classes when assessment moments occur for 2018/2019 and 2019/2020 academic years and in contrast the attendance in the other theoretical classes vary from $60 \%$ to $15 \%$, at the end of the semester.

Although Fluid Mechanics is considered a difficult core topic in many engineering areas it is the authors belief that students consider STFLU the easiest semester curricular unit (probably due to the fact that it is the unit with the highest approval percentages of the semester) and consider Instrumental Methods of Analysis the most difficult one and core to the degree along with Chemical Engineering Reactors units. Bear in mind that many student's vision for their professional activity is to work in analyses laboratories which may or not be directly connected to industry.

There are many factors that might explain the results obtained but with the available questionnaire this is not possible; more indepth and specific questionnaires would have to be made.

All prior conclusions/analyses are important to decide what changes are to be made in the next academic year (2020-21) regarding the teaching and assessment methodologies. We believe that the importance is not in increasing the number of assessments but in the diversification of the type of methodologies/assessments. As 
a consequence of this study and all prior articles, a Team Based Learning (TBL) methodology will be introduced (academic year 2020-21). It will be the first time TBL will be applied in STFLU and it is planned to carry it out in at least one component of the syllabus, namely fluid's viscosity. This will correspond to substitute individual mini-test IMT1 by this new methodology for the teachers and students involved. The reason to choose TBL is because it follows a structured process which engages effectively students in a collaborative (group/team) work that stimulates student's involvement and boosts the quality of their learning [22].

In the future it will also be important to compare and identify consequences in professional performance comparing some of the prior information with the grades obtained in the Chemical Engineering degree curricular internship which is mostly carried out in industries.

\section{ACKNOWLEDGMENTS}

The authors would like to express their acknowledgment to all students who agreed to collaborate in this study. The authors also thank FCT (Fundação para a Ciência e Tecnologia) for the support of the projects FCT UIDB/04730/2020 and FCT UIDB/00319/2020 in the scope of the Research Centres CIETI (Centro de Inovação em Engenharia e Tecnologia Industrial) and ALGORITMI, respectively.

\section{REFERENCES}

[1] K. Danilowicz-Gösele, K. Lerche, J. Meya, and R. Schwager. 2017. "Determinants of students' success at university." Education Economics, vol. 25, no 5, pp. 513-532. doi:10.1080/09645292.2017.1305329

[2] T. T. York, C. Gibson, and S. Rankin. 2015. "Defining and Measuring Academic Success." Practical Assessment, Research, and Evaluation, vol. 20, Article 5. doi: https://doi.org/10.7275/hz5x-tx03

[3] J. Smith, and R. Naylor. 2005. "Schooling effects on subsequent university performance: evidence for the UK university population." Economics of Education Review, vol. 24, pp. 549-562. doi:10.1016/j.econodurev.2004.07.016

[4] P. Cyrenne, and A. Chan. 2012. "High school grades and university performance: A case study." Economics of Education Review, vol. 31, pp. 524- 542. doi: 10.1016/j.econedurev.2012.03.005

[5] B. S. Grave. 2011. "The Effect of Student Time Allocation on Academic Achievement." Education Economics, vol. 19, no. 3, pp. 291-310 doi:10.1080/09645292.2011.585794

[6] T. Zwick. 2013. "Determinants of Individual Academic Achievement: Group Selectivity Effects Have Many Dimensions." GSBE Research Memoranda, No. 13/016, Maastricht. doi: 10.26481/umagsb.2013016

[7] J. Guimarães, and B. Sampaio. 2013. "Family Background and Students' Achievement on a University Entrance Exam in Brazil." Education Economics, vol. 21, no.
1, pp. 38-59. doi:10.1080/09645292.2010.545528

[8] C. K. Spiess, and K. Wrohlich. 2010. "Does Distance Determine Who Attends a University in Germany?" Economics of Education Review, vol. 29, no. 3, pp. 470-479. doi:10.1016/j.econedurev.2009.10.009

[9] S. B Robbins, K. Lauver, H. Le, D. Davis, R. Langley, and A. Carlstrom. 2004. "Do Psychosocial and Study Skill Factors Predict College Outcomes? A Meta-Analysis." Psychological Bulletin, vol. 130, no. 2, pp. 261-288. doi:10.1037/0033-2909.130.2.261

[10] K. McKenzie, and R. Schweitzer. 2001. "Who Succeeds at University? Factors Predicting Academic Performance in First Year Australian University Students." Higher Education Research and Development, vol. 20, no. 1, pp. 21-33. doi:10.1080/07924360120043621

[11] J. D. A Parker, L. J. Summerfeldt, M. J. Hogan, and S. A. Majeski. 2004. "Emotional Intelligence and Academic Success: Examining the Transition from High School to University." Personality and Individual Differences, vol. 36, no 1, pp. 163-172. doi:10.1016/S0191-8869(03)00076-X

[12] S. Levy, and J. Murray. 2005. "Tertiary Entrance Scores Need Not Determine Academic Success: An Analysis of Student Performance in an Equity and Access Program." Journal of Higher Education Policy and Management, vol. 27, no. 1, pp 129-141. doi:10.1080/13600800500046529

[13] M. Peat, J. Dalziel, and A. M. Grant. 2001. "Enhancing the First Year Student Experience by Facilitating the Development of Peer Networks through a OneDay Workshop." Higher Education Research and Development, vol. 20, no 2, pp. 199-215. doi:10.1080/07294360123888

[14] A. C. Achen, and P. N. Courant. 2009. "What Are Grades Made of?" fournal of Economic Perspectives, vol. 23, no 3, pp. 77-92. doi:10.1257/089533009789176799

[15] I. R Dobson, and E. Skuja. 2005. "Secondary Schooling: Tertiary Entry Ranks and University Performance." People and Place, vol. 13, no 1, pp. 53-62. ISSN $1039-4788$

[16] T. Sena-Esteves, C. Morais, A., Guedes, I., Brás-Pereira, M. M. Ribeiro, F. Soares, and C. P. Leão. 2017. "Teaching Impact and Evaluation Methodology Assessment in a Fluid Mechanics Course: Student'S Perceptions." In Proceedings of the ASME 2017 International Mechanical Engineering Congress and Exposition (ASME IMECE2017), Tampa, Florida, USA. Paper No: IMECE2017-70576, V005T06A019, , 9 pages. November 3-9, 2017. https://doi.org/10.1115/IMECE2017-70576

[17] F. Soares, C. P. Leão, A. Guedes, I. Brás-Pereira, C. Morais, F. Soares, F. and T. Sena-Esteves. 2015. "Interpreting Students' Perceptions in Fluid Mechanics Learning Outcomes." Education in The Knowledge Society (EKS), vol. 16, no 3, pp. 73-89, 2015. doi: 10.14201/eks20151637390.

[18] T. Sena-Esteves, C. Morais, I. Brás-Pereira, M. Ribeiro, F. Soares, and C. P. Leão. 2019. "Students' Perceptions Regarding Assessment Changes in a Fluid Mechanics Course." Educ. Sci., vol. 9, no. 2, 152, 2019. https://doi.org/10.3390/educsci9020152

[19] A. Kolb, and D. A. Kolb. 2005. The Kolb Learning Style Inventory - Version 3.12005 Technical Specifications. HayGroup, Available at: www.hayresourcesdirect.haygroup.com/

[20] A. Field. 2009. Discovering Statistics Using SPSS; SAGE, Publications Ltd.: London, $U K$

[21] M. Teresa Sena-Esteves, Cristina Morais, Margarida Ribeiro; Isabel Brás Pereira, Anabela Guedes, Filomena Soares and Celina Pinto Leão. "Gender Differences in Students' Assessment in a Fluid Mechanics Course". In Proceedings of IEEE EDUCON2020 - Global Engineering Education Conference, 27-30 April 2020, Porto, Portugal. doi: 10.1109/EDUCON45650.2020.9125184 l

[22] VesnaNajdanovic-Visak. "Team-based learning for first year engineering students." Education for Chemical Engineers, vol. 18, pp. 26-34, 2017. doi: http://dx.doi.org/ 10.1016/j.ece.2016.09.001 